\title{
AVALIAÇÃO ECONÔMICA DAS PERDAS DE BANANA NO MERCADO VAREJISTA: UM ESTUDO DE CASO'
}

\author{
CINTIA DE SOUZA SILVA², JOSÉ MATHEUS YALENTI PEROSA ${ }^{3}$, PAULO SÉRGIO RUA ${ }^{4}$, CARLOS LUIZ MILHOMEM \\ DE ABREU ${ }^{5}$, SILVIO CÉSAR PÂNTANO ${ }^{6}$, CÁSSIA REGINA YURIKO IDE VIEIRA ${ }^{7}$, RUBEM MARCO DE OLIVEIRA \\ BRIZOLA $^{8}$
}

RESUMO - O objetivo do presente estudo foi a determinação das perdas físicas e econômicas de banana em diferentes equipamentos varejistas na Cidade de Botucatu - SP e suas possíveis causas. Os equipamentos foram sorteados aleatoriamente. As informações foram coletadas através da aplicação de questionário para a determinação das perdas de três variedades de banana. O resultado mostrou perda global de 39 toneladas, correspondente a $11,1 \%$ da quantidade comercializada, sendo $10,5 \%$ em supermercados, $15,0 \%$ em quitandas/sacolões e $10,6 \%$ em feiras livres. $\mathrm{O}$ valor total das perdas anuais atingiu $\mathrm{R} \$ 35.038,00$, em valores de maio de 2002. A manipulação excessiva do cliente, excedente de oferta, uso de embalagem inadequada e baixa qualidade da fruta foram as principais causas de perdas. Conclui-se pela necessidade de conscientização do cliente, do uso de embalagens plásticas e de cuidados no manuseio da fruta durante toda pós-colheita.

Termos para indexação: banana, perdas, varejo.

\section{ECONOMIC AVALIATION OF THE BANANA'S LOSSES IN RETAIL TRADE: A CASE STUDY}

\begin{abstract}
The objective of this research was to determinate the physics and economic banana's loss and its possible reason, in several retail trades in the city of Botucatu - SP. The equipments were drawn aleatory. The information were collected through questions applied to people to determine the annual loss of three different varieties of banana. The results showed that all loss was 39 ton., that represents $11,1 \%$ of all saled in retail trades, with $10,5 \%$ in supermarkets, $15 \%$ in grocery store/retail shops, and 10,6\% in free markets. The retail trade showed an annual loss of R $\mathrm{R} \$$ $35.038,00$, in values of may/2002. The excessive handling by the client, excess offering inadequate packing, and low quality of fruit were the most important cause of losses. It was possible to conclude that, the client's behavior should be better, the plastic packing utilization, and caution in the handling during all the post harvest process.
\end{abstract}

Index terms: banana, loss, retail

\section{INTRODUÇÃO}

A competitividade pode ser considerada como um indicador de resultado e medida pelo desempenho de empresas no mercado, refletindo vantagens adquiridas ao longo do tempo. Depende de relações sistêmicas, já que muitas vezes as estratégias empresariais podem ser dificultadas por gargalos de coordenação vertical ou de logística (Jank, 2000). No processo de aquisição de competitividade em sistemas agroalimentares, é de fundamental importância a coordenação e monitoramento dos agentes da produção, agroindústria, atacado, varejo e consumidor final (Spers, 1993).

A organização mais eficiente nessas cadeias depende das características do produto e do mercado. Lideranças tradicionais, relações rígidas de classe, individualismo, dispersão espacial e falta de comunicação entre os agentes ao longo da cadeia dificultam uma coordenação mais eficiente (Weiss \& Ramponi, 1981). Um dos fatores que contribuem para uma postura cooperativa é a transparência nas relações, onde informações sobre a participação de cada elo sejam do conhecimento de todos.

As perdas pós-colheita dos produtos agrícolas podem refletir um grau de desarticulação nestes sistemas, influindo diretamente na competitividade.

O conhecimento pelos agentes da cadeia de influência dessas perdas em cada elo não se apresenta de forma transparente. Segundo Brant (1980) e Barros (1987), produtos perecíveis e com maiores taxas de perda, como hortaliças e frutas, apresentam margens totais de comercialização relativamente maiores que produtos menos perecíveis, como cereais e grãos.
A banana é um dos produtos onde esta questão é relevante. Fruta mais consumida no mundo e no Brasil, representa no âmbito nacional uma produção de aproximadamente 6 milhões de toneladas/ano (Fao, 2001). A cultura da banana ocupa o segundo lugar em volume de frutas produzidas no Brasil, perdendo apenas para a laranja (Almeida et al, 2001).O consumo aparente per capita da banana no Brasil é estimado em torno de $20 \mathrm{~kg} / \mathrm{hab}$./ano, tendo se reduzido na década de 90 , por efeito-substituição causado pela entrada de outras frutas no mercado, a preços convidativos e de boa qualidade (Mascarenhas, 1999).

O elevado índice de perdas na comercialização de banana no Brasil faz com que apenas uma parcela, entre 50 a $60 \%$ da produção, chegue à mesa do consumidor (Mascarenhas, 1999). Esses valores são semelhantes aos publicados pela Fundação Getúlio Vargas (FGV), onde estas perdas ficam em torno de 40\%. (BALANÇO..., 1991). Estudo desenvolvido por Souza et al., 1995, determinou as perdas em diferentes etapas na cadeia da banana no Brasil: na lavoura (mais de 5\%); no processo de embalagem (mais de $2 \%$ ); no atacado (de 6\% a 10\%); no varejo (de $10 \%$ a $15 \%$ ) e, no consumidor (de $5 \%$ a $8 \%$ ).

Em pesquisa sobre perdas na comercialização de produtos hortícolas na cidade de São Paulo em 1972/73, Ueno (1976) constatou diferenças acentuadas de perdas físicas entre produtos e equipamentos varejistas. Os maiores índices ocorreram nos supermercados e os menores, nas feiras livres, com índices intermediários nas quitandas, com um valor médio geral de 33\%. Já Tsunechiro et al (1994), através de pesquisa semelhante realizada em 1991/92, determinou que as quitandas apresentavam os menores índices de perdas, seguidas dos supermercados e por fim das feiras livres, com perda média da banana em torno de $10 \%$.

Em outro estudo realizado no mercado de frutas e hortaliças

\footnotetext{
${ }^{1}$ (Trabalho 179/2002). Recebido: 21/10/2002. Aceito para publicação: 30/05/2003.

${ }^{2}$ Pós graduando do curso de mestrado em Horticultura da FCA/UNESP, Botucatu. E-mail: cintiasilva@ fca.unesp.br. 6802.7164; e-mail:dede@fca.unesp.br.

${ }^{4}$ Engenheiro Florestal. E-mail: b.pedaserra@ig.com.br.

${ }^{5}$ Pós-graduando do curso de doutorado em Horticultura da FCA/UNESP, Botucatu. E-mail: camilhomem@fca.unesp.br.

${ }^{6}$ Pós-graduando do curso de doutorado em Horticultura da FCA/UNESP, Botucatu. E-mail: pantano@ fca.unesp.br.

${ }^{7}$ Pós-graduando do curso de doutorado em Horticultura da FCA/UNESP, Botucatu. E-mail: cassiar@fca.unesp.br.

${ }^{8}$ Pós-graduando do curso de doutorado em Horticultura da FCA/UNESP, Botucatu. E-mail: brizola@ fca.unesp.br.
}

${ }^{3}$ Prof. Assistente Doutor do Departamento de Gestão e Tecnologia Agroindustrial, Faculdade de Ciências Agronômicas da UNESP, campus de Botucatu, Fone: 14- 
junto ao setor supermercadista do Estado de São Paulo (jun/ago de 98$)^{9}$, o Ministério da Integração constatou que em relação às frutas, $83 \%$ de suas perdas se localizavam na exposição do produto na loja, sendo que o principal fator desta perda ocorria devido ao grande manuseio pelo consumidor. A falta de qualidade dos produtos, excedente de oferta, falta de refrigeração e tipo de embalagem, compunham as demais causas das perdas.

As perdas econômicas que o varejo sofre em relação às perdas físicas de seus produtos são repassadas ao consumidor, o que pode comprometer o consumo da fruta em relação a concorrentes; da mesma forma, pode rebaixar o valor recebido pelos produtores, comprometendo o investimento na cultura e afetando a competitividade de toda a cadeia.

As causas destas perdas não estão associadas unicamente à distribuição, mas a todos os agentes envolvidos na produção e comercialização.

O presente estudo visa determinar as perdas econômicas na pós-colheita da banana e suas causas, oferecendo subsídios e contribuindo para uma maior transparência aos agentes dessa cadeia agroalimentar.

\section{MATERIALEMÉTODOS}

A avaliação das perdas de banana foi realizada através de levantamento junto a equipamentos de varejo na cidade de BotucatuSP.

De acordo com a National Academy of Sciences (1982), avaliação constitui uma aproximação das perdas dos alimentos, se contrapondo à medição que é um processo mais preciso e objetivo. $\mathrm{O}$ uso desse termo tem implícito, portanto, um grau de subjetividade decorrente da dificuldade de obtenção de informação mais precisa.

O conceito de perda, nesta pesquisa, se baseia em Carvalho (1992), que a define como reduções na quantidade física do produto disponível para o consumo, que podem vir acompanhadas por uma redução na qualidade, diminuindo o valor comercial ou nutritivo do produto.

Os equipamentos varejistas pesquisados foram conceituados segundo Barros et al (1978), que define:

Supermercado

É o principal representante dos estabelecimentos de autoserviço, caracterizado pela escolha das mercadorias pelo próprio consumidor, que transporta até a caixa registradora, onde realiza o pagamento, sem necessidade de interferência ou ajuda de balconista. Em estudo realizado por Weiss \& Ramponi (1981), determinou-se que, atualmente, prevalecem em alguns supermercados, preços de hortigranjeiros inferiores àqueles vigorantes nas feiras, porém na grande maioria das vezes, o estabelecimento nivela os preços por cima, levando em conta o preço nas feiras, especialmente nas praças em que o número de grandes empresas varejistas é menor.

Quitanda

Equipamento fixo de venda a varejo, especializado na distribuição de produtos hortigranjeiros. Muitas delas tem diversificado sua linha, colocando à venda latarias. São firmas pequenas, abastecidas de acordo com o programa do proprietário, não possuindo equipamentos adequados ao armazenamento dos produtos. O sacolão apresenta características semelhantes na cidade de Botucatu.

\section{Feira - Livre}

Equipamento varejista móvel, cuja característica principal é a circulação de instalações provisórias nas vias publicas. O feirante tem possibilidades de realizar compras diretas do produtor (às vezes é a mesma pessoa), permitindo-lhe vender ao consumidor a preços mais convenientes.

Foram consideradas três variedades na pesquisa: Nanica, Prata e Maçã. Os dados foram levantados junto a três tipos de equipamento varejista (supermercado, quitanda/sacolão e feira livre), na cidade de Botucatu - SP. Ao todo foram pesquisados 18 equipamentos ( 9 supermercados, 6 quitanda/sacolões e 3 feirantes), sorteados aleatoriamente. Para os dois primeiros, o tamanho destas sub-amostras representa aproximadamente $20 \%$ do total de cada equipamento, determinado através de levantamento junto a comerciantes da cidade de Botucatu. $\mathrm{O}$ número de feirantes foi determinado por critério intencional, baseado no fato de existir uma única feira livre que se desloca pela cidade.

Os levantamentos de dados foram realizados mediante aplicação de questionário, em maio/junho de 2002, diretamente com os encarregados do setor de hortifruti (no caso de supermercados), e com os proprietários de quitanda/sacolão e feirantes.

Para avaliação do valor econômico das perdas de cada variedade, foram utilizados os seguintes dados e informações:

- Volume mensal comercializado de cada variedade de banana, nos principais atacadistas de hortifrutícolas da cidade de Botucatu, e seu destino junto aos diferentes equipamentos varejistas. Esses dados foram levantados através da aplicação de questionário;

- $\quad$ Percentuais de perda (médias ponderadas por equipamento de varejo), com base nos dados da pesquisa.

Preço médio: determinado através do preço médio de venda no mercado varejista de Botucatu, corrigido para o mês de maio no ano, através dos preços médios mensais.

Os preços foram corrigidos pelo Índice Geral de Preços - IGPDI para valores de maio de 2002.

\section{RESULTADOS E DISCUSSÃO}

A Tabela 1 apresenta o volume estimado de banana comercializada no município de Botucatu. Destaca-se a variedade nanica, seguida da prata e maçã (Tabela 1), onde o consumo de banana nanica é superior ao consumo das demais variedades da fruta. Vale destacar que a banana nanica apresenta os menores preços de venda, devendo este fato estar relacionado com o seu maior consumo.

A Tabela 1 também mostra a participação do supermercado na comercialização da banana, em torno de $78 \%$, seguidos da quitanda/ sacolão e feira livre, com respectivamente $12,3 \%$ e $9,7 \%$. O setor supermercadista nacional é responsável por cerca de $85 \%$ do abastecimento de gêneros alimentícios e de higiene e limpeza. De acordo com FRUTIFATOS (1999), 47\% dos consumidores preferem comprar hortifruti nos supermercados, devido, principalmente, à higiene, forma de exposição para venda e praticidade no ato da compra. O segundo lugar de preferência, com $27 \%$, são as feiras livres, devido à qualidade e com $21 \%$ de preferência as quitandas/sacolões, que segundo os consumidores apresentam menores preços.

Dimensão das perdas de banana no mercado varejista. As perdas médias de banana no mercado varejista da cidade de Botucatu foram de $11,1 \%$ do volume comercializado. Verificaram-se as seguintes perdas médias por tipo de equipamento: $10,5 \%$ em supermercados, $15,0 \%$ em quitandas/sacolões e 10,6\% em feiras livres (Tabela 2).

Comparando os resultados desta pesquisa com os de Ueno (1976), constata-se uma acentuada redução de perdas nos supermercados, de $22 \%$ para $10,5 \%$, e de $12,0 \%$ para $10,6 \%$ nas feiras livres. Em relação aos dados obtidos por Tsunechiro (1994), constata-se uma pequena redução para os supermercados (de 13,2\% para 10,5\%) e uma elevação para as feiras livres (de 8,2\% para 10,6\%). Para as quitandas/ sacolões não é possível a comparação, já que na referida pesquisa somente as quitandas foram analisadas.

As menores perdas nos supermercados e sua redução ao longo dos anos podem ser atribuídas a diversos fatores. Ressalta-se o diferencial de organização estrutural, eficiência no controle de suprimentos e administração de estoque (Tsunechiro, 1994). Segundo Frutifatos (1999), os supermercados dispõem de boa infra-estrutura para operação com os hortifruti, e vêm aprimorando suas estratégias

${ }^{9}$ Citado por FRUTIFATOS (1999)

Rev. Bras. Frutic., Jaboticabal - SP, v. 25, n. 2, p. 229-234, Agosto 2003 
TABELA 1 - Volume mensal de banana comercializada na cidade de Botucatu/SP, em cx de $20 \mathrm{Kg}$.

\begin{tabular}{|c|c|c|c|c|c|c|}
\hline Variedade & Equipamento & Atacadista 1 & Atacadista 2 & Atacadista 3 & Total Geral & $\%$ \\
\hline \multirow{4}{*}{ Nanica } & Supermercado & 60,0 & 360,0 & 385,0 & 805,0 & 75,2 \\
\hline & Quitanda/sacolão & 30,0 & 20,0 & 110,0 & 160,0 & 15,0 \\
\hline & Feira livre & 30,0 & 20,0 & 55,0 & 105,0 & 9,8 \\
\hline & Sub total 1 & 120,0 & 400,0 & 650,0 & 1070,0 & 100,0 \\
\hline \multirow{3}{*}{ Maça } & Supermercado & 5,0 & 80,0 & 13,5 & 98,5 & 78,8 \\
\hline & Quitanda/sacolão & 2,5 & 10,0 & 1,5 & 14,0 & 11,2 \\
\hline & Sub total 2 & 10,0 & 100,0 & 15,0 & 125,0 & 100,0 \\
\hline \multirow{4}{*}{ Prata } & Supermercado & 5,0 & 120,0 & 27,0 & 152,0 & 80,0 \\
\hline & Quitanda/sacolão & 2,5 & 15,0 & 3,0 & 20,5 & 10,8 \\
\hline & Feira livre & 2,5 & 15,0 & 0,0 & 17,5 & 9,2 \\
\hline & Sub total 3 & 10,0 & 150,0 & 30,0 & 190,0 & 100,0 \\
\hline
\end{tabular}

de compra, passando a exigir de seus fornecedores mercadorias de melhor qualidade, podendo, portanto, reduzir seus níveis de perdas.

Outro fator para os menores índices de perdas é a utilização de expositores (Tabela 7). Neste caso, a inadequada manipulação dos produtos pelos consumidores provoca sua deterioração, elevando as perdas totais. Os expositores acabam diminuindo a manipulação dos consumidores, devido à distribuição das pencas de forma separada, diminuindo, portanto, as perdas. Verificou-se acentuada diferença das perdas médias entre os supermercados com expositores $(5,6 \%)$, e os supermercados com gôndolas a temperatura ambiente $(14,7 \%)$.

TABELA 2 - Porcentagem das perdas de banana no mercado varejista da Cidade de Botucatu/SP, em relação ao volume comercializado $(\%)$.

\begin{tabular}{lcccc}
\hline Variedade & Supermercado & $\begin{array}{c}\text { Quitanda } \\
\text { Sacolão }\end{array}$ & $\begin{array}{c}\text { Feira } \\
\text { livre }\end{array}$ & Média $^{\mathbf{1}}$ \\
\hline Nanica & 11,7 & 15,0 & 11,7 & 12,1 \\
Prata & 10,0 & 15,0 & 10,0 & 10,6 \\
Maçã & 9,9 & 15,0 & 10,0 & 11,5 \\
\hline Média & 10,5 & 15,0 & 10,6 & 11,1 \\
\hline
\end{tabular}

${ }^{1}$ Ponderada pela participação do equipamento na venda de banana

TABELA 7 - Porcentagem da forma de exposição e da freqüência de compras de banana pelos equipamentos varejistas da $\mathrm{Ci}$ dade de Botucatu/SP.

\begin{tabular}{lll}
\hline Equipamento & $\begin{array}{c}\text { Forma de exposição } \\
\text { da fruta }\end{array}$ & $\begin{array}{c}\text { Freqü ência de Compras } \\
\text { da fruta }\end{array}$ \\
\hline Supermercado & $25 \%$ expositores & $25 \%$ diariamente \\
& $75 \%$ gôndolas a $\mathrm{T}^{\circ}$ ambiente & $75 \% 1$ a 3 vezes $/$ semana \\
\hline Quitanda/sacolão & $100 \%$ gôndolas a $\mathrm{T}^{\circ}$ ambiente & $100 \% 1$ a 3 vezes $/$ semana \\
\hline Feira -livre & $100 \%$ gôndolas a $\mathrm{T}^{\circ}$ ambiente & $100 \% 1$ a 3 vezes $/$ semana \\
\hline
\end{tabular}

Ressalta-se também que $25 \%$ dos supermercados realizam suas compras diariamente, ocorrendo menor tempo entre compra e venda da banana (Tabela 7). Assim, as frutas não precisam ficar armazenadas ou estocadas, quando perdem sua qualidade, aumentando o risco de perda.

As feiras apresentaram níveis de perda semelhante aos supermercados. Destaca-se o fato de que as compras são feitas pelo próprio feirante com baixo volume e pequena diversificação (Amaro, 1989). Estes dão particular atenção a itens importantes na determinação da preferência dos consumidores, como variedade e qualidade de cada produto (Tsunechiro, 1994), podendo, assim minimizar as perdas. Ainda verificase que é o próprio feirante que serve o consumidor, diminuindo as possíveis perdas causadas pela excessiva manipulação deste.

As perdas referentes às quitandas/sacolões foram as mais acentuadas dos equipamentos de varejo. As compras de mercadoria são realizadas entre 1 a 3 dias (tabela 7). A estocagem de produtos chega a 6 dias, com reflexos nas perdas. A exposição em sacolões é feita em espaços relativamente amplos, com grande variedade de produtos, dificultando o controle na manipulação dos clientes e no controle de estoques.

A banana nanica apresentou maiores perdas, sendo que a prata e a maçã apresentaram perdas semelhantes. A compra destas duas variedades se dá de forma mais controlada, tendo como base o consumo já conhecido destas frutas, causando, portanto, menores perdas.

Valor econômico das perdas de banana - $O$ volume de perda mensal das três variedades de banana atingiu 3,25 toneladas, correspondente a $11,1 \%$ do total comercializado nos três equipamentos de varejo. O valor total das perdas anuais no mercado varejista atingiu $R \$ 35.038,00$ mil reais (Tabela 3 ). As perdas foram de $\mathrm{R} \$ 25.610,92 \mathrm{em}$ supermercados, $\mathrm{R} \$ 6.119,80 \mathrm{em}$ quitandas/sacolões e R \$3.492,24 em feiras livres (Tabelas 4, 5 e 6).

As perdas nos supermercados representaram $73,1 \%$ do valor total das perdas e se deve basicamente a sua maior participação relativa $(76,2 \%)$ no volume de banana comercializada. O mesmo se verifica para a variedade nanica, que apresentou a perda mais significativa $(79,7 \%)$, influenciado pelo respectivo volume físico comercializado.

TABELA 3 - Valor das perdas na comercialização da banana no mercado varejista, da Cidade de Botucatu/SP.

\begin{tabular}{|c|c|c|c|c|c|c|c|}
\hline \multirow{2}{*}{ Variedade } & \multirow{2}{*}{$\begin{array}{c}\text { Quant. } \\
\text { Comercializada (cx) }\end{array}$} & \multirow{2}{*}{$\begin{array}{c}\text { Quant. } \\
\text { Comercializada }^{1}(t)\end{array}$} & \multirow{2}{*}{ Perda Média (\%) } & \multirow{2}{*}{ Quant. Perdida (t) } & \multirow{2}{*}{ P. Médio $^{2}(\mathrm{R} \$ / \mathrm{Kg})$} & \multicolumn{2}{|c|}{ Valor da perda (R\$) } \\
\hline & & & & & & Mensal & Anual $^{3}$ \\
\hline Nanica & 1.070 & 21,40 & 12,1 & 2,59 & 0,80 & $2.072,00$ & $23.952,07$ \\
\hline Prata & 190 & 3,80 & 10,6 & 0,40 & 1,39 & 556,00 & $6.427,29$ \\
\hline Maçã & 125 & 2,50 & 10,5 & 0,26 & 1,55 & 403,00 & $4.658,63$ \\
\hline Total & 1.385 & 27,70 & 11,1 & 3,25 & - & $3.031,00$ & $35.038,00$ \\
\hline
\end{tabular}

${ }^{1}$ Considerou-se que cada caixa equivale a $20 \mathrm{~kg}$ da fruta.

${ }^{2}$ Preço corrigido (IGP-DI) através de fator de correção referente à participação do mês de maio no ano. (Fonte: IEA, 2002)

${ }^{3} \mathrm{O}$ valor da perda foi calculado através de fator de correção referente à participação do mês de maio no total anual comercializado na CEAGESP. 
TABELA 4 - Valor das perdas na comercialização da banana nos supermercados, da Cidade de Botucatu/SP.

\begin{tabular}{|c|c|c|c|c|c|c|c|}
\hline \multirow[t]{2}{*}{ Variedade } & \multirow{2}{*}{$\begin{array}{l}\text { Quant. } \\
\text { Comercializada (cx) }\end{array}$} & \multirow{2}{*}{$\begin{array}{c}\text { Quant. } \\
\text { Comercializada }^{1}(t)\end{array}$} & \multirow{2}{*}{$\begin{array}{c}\text { Perda } \\
\text { Média (\%) }\end{array}$} & \multirow{2}{*}{ Quant. Perdida (t) } & \multirow{2}{*}{$\begin{array}{l}\text { P. Médio }{ }^{2} \\
\text { (R\$/Kg }\end{array}$} & \multicolumn{2}{|c|}{ Valor da Perda (R\$) } \\
\hline & & & & & & Mensal & Anual $^{3}$ \\
\hline Nanica & 805,0 & 16,10 & 11,7 & 1,88 & 0,80 & $1.504,00$ & $17.386,06$ \\
\hline Prata & 152,0 & 3,04 & 10,0 & 0,30 & 1,39 & 417,00 & $4.820,47$ \\
\hline Maçã & 98,5 & 1,97 & 9,9 & 0,19 & 1,55 & 294,50 & $3.404,39$ \\
\hline Total & 1055,5 & 21,11 & 10,5 & 2,37 & - & $2.215,50$ & $25.610,92$ \\
\hline
\end{tabular}

Caixa com $20 \mathrm{~kg}$ da fruta.

${ }^{2}$ Preço corrigido (IGP-DI) através de fator de correção referente à participação do mês de maio no ano. (Fonte: IEA,2002)

${ }^{3} \mathrm{O}$ valor da perda foi calculado através de fator de correção referente à participação do mês de maio no total anual comercializado na CEAGESP.

TABELA 5 - Valor das perdas na comercialização da banana nas quitandas/sacolões, da Cidade de Botucatu/SP.

\begin{tabular}{|c|c|c|c|c|c|c|c|}
\hline \multirow{2}{*}{ Variedade } & \multirow{2}{*}{$\begin{array}{l}\text { Quant. } \\
\text { Comercializada (cx) }\end{array}$} & \multirow{2}{*}{$\begin{array}{c}\text { Quant. } \\
\text { Comercializada }^{1}(t)\end{array}$} & \multirow{2}{*}{$\begin{array}{c}\text { Perda } \\
\text { Média (\%) }\end{array}$} & \multirow{2}{*}{$\begin{array}{c}\text { Quant. } \\
\text { Perdida (t) }\end{array}$} & \multirow{2}{*}{$\begin{array}{l}\text { Preço Médio }^{2} \\
\text { (R\$/Kg) }\end{array}$} & \multicolumn{2}{|c|}{ Valor da perda $(\mathrm{R} \$)$} \\
\hline & & & & & & Mensal & Anual $^{3}$ \\
\hline Nanica & 160,0 & 3,2 & 15,0 & 0,48 & 0,80 & 384,00 & $4.438,99$ \\
\hline Prata & 20,5 & 0,41 & 15,0 & 0,06 & 1,39 & 83,40 & 964,09 \\
\hline Maçã & 14,0 & 0,28 & 15,0 & 0,04 & 1,55 & 62,00 & 716,71 \\
\hline Total & 194,5 & 3,89 & 15,0 & 0,58 & - & 529,40 & $6.119,80$ \\
\hline
\end{tabular}

${ }^{1}$ Considero-se que cada caixa equivale a $20 \mathrm{~kg}$ da fruta.

${ }^{2}$ Preço corrigido (IGP-DI) através de fator de correção referente à participação do mês de maio no ano. (Fonte: IEA,2002)

${ }^{3} \mathrm{O}$ valor da perda foi calculado através de fator de correção referente à participação do mês de maio no total anual comercializado na CEAGESP.

TABELA 6 - Valor das perdas na comercialização da banana nas feiras livres, da Cidade de Botucatu/SP.

\begin{tabular}{|c|c|c|c|c|c|c|c|}
\hline \multirow[t]{2}{*}{ Variedade } & \multirow{2}{*}{$\begin{array}{c}\text { Quant. } \\
\text { Comercializada (cx) } \\
\end{array}$} & \multirow{2}{*}{$\begin{array}{c}\text { Quant. } \\
\text { Comercializada }^{1}(t) \\
\end{array}$} & \multirow{2}{*}{$\begin{array}{c}\text { Perda } \\
\text { Média (\%) }\end{array}$} & \multirow{2}{*}{$\begin{array}{c}\text { Quant. } \\
\text { Perdida (t) }\end{array}$} & \multirow{2}{*}{$\begin{array}{c}\text { Preço Médio }^{2} \\
\text { (R\$/Kg) }\end{array}$} & \multicolumn{2}{|c|}{ Valor da perda (R\$) } \\
\hline & & & & & & Mensal & Anual $^{3}$ \\
\hline Nanica & 105,0 & 2,10 & 11,7 & 0,25 & 0,80 & 200,00 & $2.311,98$ \\
\hline Prata & 17,5 & 0,35 & 10,0 & 0,04 & 1,39 & 55,60 & 642,73 \\
\hline Maça & 12,5 & 0,25 & 10,0 & 0,03 & 1,55 & 46,50 & 537,53 \\
\hline Total & 135,0 & 2,70 & 10,6 & 0,32 & - & 302,10 & $3.492,24$ \\
\hline
\end{tabular}

${ }^{1}$ Considero-se que cada caixa equivale a $20 \mathrm{~kg}$ da fruta.

${ }^{2}$ Preço corrigido (IGP-DI) através de fator de correção referente à participação do mês de maio no ano. (Fonte: IEA,2002)

${ }^{3} \mathrm{O}$ valor da perda foi calculado através de fator de correção referente à participação do mês de maio no total anual comercializado na CEAGESP.

Principais causas de perdas e sua relação com os diferentes equipamentos de varejo - Os fatores causadores de perdas são mostrados na Tabela 8. A principal causa revelada na pesquisa é a manipulação excessiva nas frutas e hortaliças pelos clientes. Tsunechiro (1994) e FRUTIFATOS (1999) obtiveram esta mesma realidade em seus trabalhos. O resultado mostra a grande preocupação dos supermercadistas para este fato, que se justifica pela dificuldade no controle pontual junto a seus consumidores. O mesmo é verificado nas quitandas/sacolões. Entretanto, há indicações que o feirante não tem esta mesma preocupação, já que é este quem geralmente serve o consumidor, diminuindo as perdas causadas por manipulação excessiva.

Outro fator apontado como indutor de perdas é o excedente de oferta. Este dado revela pouca eficiência no controle de estoques por estes equipamentos, uma vez que o excedente de oferta está relacionado com má administração. Pela Tabela 8 verifica-se que este fator é determinante para as perdas nas quitandas/sacolões e feiras livres. O controle de estoque é uma das sugestões dos varejistas para minimizar as perdas (tabela 9).

O uso de embalagens inadequadas também foi citado como um grande causador de perdas, sendo sugerido modificações em relação ao seu material ${ }^{10}$ como o uso de embalagens de plástico (Tabela 9), em substituição às atuais de madeira. Sabe-se também que para garantir o peso desejado da banana embalada na comercialização é necessário, no momento do acondicionamento nas embalagens, a compressão das frutas contra as outras e contra a própria embalagem, gerando danos físicos às mesmas. Portanto, mudanças no tamanho das embalagens ou no peso final do produto embalado, além das alterações no material, se fazem necessário, visando manter a qualidade do produto ao longo de toda a cadeia de comercialização da banana.

Os dados apresentados na Tabela 8 mostram que para o setor supermercadista, o preço é um dos principais fatores que influencia em suas perdas. Diferentemente para as quitandas/sacolões e feiras livres o preço não é citado. O maior causador de perdas é a falta de controle na compra e venda dos produtos pelos equipamentos.

TABELA 8 - Motivos causadores de perdas de banana, segundo a visão dos equipamentos varejistas da Cidade de Botucatu/SP.

\begin{tabular}{|c|c|c|c|c|}
\hline \multirow{2}{*}{ Motivo } & \multicolumn{3}{|c|}{$\%$ de respostas } & \multirow{2}{*}{ Média $^{1}$} \\
\hline & Supermercado & Quitanda/sacolão & Feira-livre & \\
\hline Manipulação excessiva do cliente & 75,0 & 50,0 & 0,0 & 64,2 \\
\hline Excedente de Oferta & 50,0 & 50,0 & 100,0 & 54,8 \\
\hline Embalagens inadequadas & 25,0 & 25,0 & 66,5 & 29,2 \\
\hline Baixa qualidade da fruta & 12,5 & 25,0 & 66,5 & 19,5 \\
\hline Más condições de transporte & 12,5 & 0,0 & 66,5 & 16,0 \\
\hline Preços elevados & 62,5 & 0,0 & 0,0 & 47,6 \\
\hline Forma de exposição da fruta & 12,5 & 0,0 & 33,5 & 12,8 \\
\hline Armazenamento inadequado & 0,0 & 0,0 & 33,5 & 3,2 \\
\hline Falta de padronização da fruta & 0,0 & 0,0 & 0,0 & 0,0 \\
\hline
\end{tabular}

${ }^{1}$ Ponderada pela participação do equipamento na venda de banana

${ }^{10}$ A participação do uso de embalagens de madeira foi de $100 \%$ em todos os equipamentos entrevistados. 
TABELA 9 - Sugestões oferecidas a fim de diminuir as perdas de banana pelos equipamentos varejistas da Cidade de Botucatu/SP.

\begin{tabular}{lcccc}
\multicolumn{1}{c}{ Motivo } & Supermercado & $\begin{array}{c}\text { \% de respostas } \\
\text { Quitanda/sacolão }\end{array}$ & Feira-livre & Média $^{\mathbf{1}}$ \\
\hline Conscientização do cliente & 33,3 & 33,3 & 0,0 & 30,0 \\
Uso de embalagens plásticas & 22,2 & 16,7 & 33,3 & 22,5 \\
Controle de estoque & 11,1 & 16,7 & 33,3 & 3,3 \\
Cuidados na ma nipulação da fruta & 11,1 & 0,0 & 33,3 & 14,0 \\
Cuidados no transporte da fruta & 11,1 & 0,0 & 0,0 & 11,7 \\
Uso de armazenamento refrigerado & 11,1 & 0,0 & 0,0 & 8,5 \\
Compra de fruta regional & 11,1 & 0,0 & 0,0 & 8,5 \\
Compra da fruta menos madura & 11,1 & 0,0 & 8,5 \\
\hline
\end{tabular}

Ponderada pela participação do equipamento na venda de banana

As sugestões apresentadas pelos equipamentos de varejo para redução das perdas revelam uma situação diferenciada. Durante as entrevistas notou-se intensa preocupação das quitandas/sacolões e feiras livres em relação ao domínio na comercialização de hortifruti pelos supermercados, reivindicando políticas que regulamentem a exploração do mercado pelo monopólio supermercadista. Este fato revela a fragilidade na comercialização destes equipamentos, que enfatizaram sua deficiência desde o aumento considerável no número de grandes redes de supermercados.

A atual tendência no mercado de frutas e hortaliças é a concentração da comercialização pelo setor supermercadista, diminuindo a participação dos atacadistas e outros equipamentos de varejo. Este fato pode ser confirmado nos estudos realizados pelo FRUTIFATOS (1999), que descreve o aumento da área destinada a hortifruti nos supermercados, crescendo de 30 para $60 \%$ nos últimos 10 anos. Ainda, de acordo com o estudo, com as novas variedades de frutas e hortaliças, o setor supermercadista tem procurado novas formas de apresentação e exposição, buscando manter e atrair novos clientes, refletindo em uma participação de $10 \%$ do faturamento global do setor.

A conscientização do cliente, visando diminuir a manipulação nas frutas e hortaliças, é a sugestão mais recomendada a fim de diminuir suas perdas (tabela 9). Mudanças de hábitos do consumidor são demoradas e normalmente se verifica de forma abrangente, extrapolando as condições locais. A segunda sugestão mais indicada foi o uso de embalagens plásticas. Visto que este fator depende de mudanças estruturais na cadeia agroindustrial da banana, também nesse caso fica evidenciada sua transformação lenta e dependente de diversos fatores.

Verifica-se, portanto, que as sugestões de maior relevância para os equipamentos de varejo, dado seu próprio poder de influência, ficaram em segundo plano, como: controle de estoques, compra regional de frutas, armazenamento refrigerado e compra da fruta menos madura. Certamente, em curto prazo, nem todos os equipamentos tem condições de viabilizarem tais mudanças, mas seria importante a percepção da capacidade de transformação possível por estes equipamentos.

Foi determinado ainda a relação de perdas da banana com as demais frutas. As respostas indicaram que as perdas de banana são semelhantes às demais frutas em $47 \%$ dos equipamentos, superior em $20,8 \%$ e inferior em $32,0 \%$. Segundo Tsunechiro (1994), as frutas que apresentam as maiores perdas são o mamão e a manga, e as menores perdas, o limão e a laranja. De acordo com as entrevistas, a perda superior da banana em relação às demais frutas foi justificada pela sua grande perecibilidade. Peculiarmente, o inverso foi explicado pelo fato da banana, mesmo em estágio avançado de amadurecimento, encontrar demanda pelo seu emprego em doces e compotas, reduzindo as perdas totais.

\section{CONCLUSÕES}

1) A comercialização da banana é feita predominantemente pelo setor supermercadista $(76,2 \%)$. Este dado confirma resultados de outros estudos, com a tendência dos supermercados concentrarem a comercialização de frutas e hortaliças, diminuindo a participação dos atacadistas e outros equipamentos de varejo.
2) O volume global da perda anual das três variedades de banana, na cidade de Botucatu, somou 39 toneladas, representando um valor de $\mathrm{R} \$ 35.038,00$ mil reais. Esse volume de perdas deve influir significativamente no processo de formação de preços ao longo da cadeia, com consequiências na quantidade demandada. Mudanças pontuais podem reduzir essas perdas, tais como gerenciamento de estoques e exposição da fruta, com benefícios para toda a cadeia.

3) Dado que um perfeito controle de estoques é um processo complexo e demorado, são imprescindíveis outras ações dentro dos equipamentos varejistas que possam garantir a qualidade dos produtos por um maior período de tempo como: uso de refrigeração, embalagem e expositores. Entretanto, é vital para a otimização do sistema uma maior exatidão no volume de compra dos produtos, baseado no consumo prédeterminado, com o uso de planilhas de vendas, pesquisa de mercado e estudos de sazonalidade de consumo, pelos equipamentos varejistas.

4) As sugestões apresentadas para redução das perdas estão baseadas, prioritariamente, em mudanças culturais e estruturais ao longo da cadeia. A consciência de que as perdas são um reflexo de uma série de atividades ao longo de um sistema, é de fundamental importância para as transformações nos índice de perdas no longo prazo, devendo fazer parte de um planejamento estratégico. Entretanto, como já exposto, mudanças emergenciais podem ser realizadas (uso de refrigeração, compra da fruta regional e menos madura, maior controle na compra). Essa informação sugere a necessidade de maiores investimentos em treinamento de capacitação técnica para os encarregados do setor de frutas e hortaliças.

5) Finalmente, tornam-se relevantes estudos mais aprofundados que procurem dimensionar o custo que a sociedade paga pela perda de outras frutas essenciais à dieta alimentar da população. Evidentemente, pesquisas desta natureza são muito onerosas e de difícil execução, sendo recomendável estudos de casos em regiões e municípios representativos do país.

\section{REFERÊNCIASBIBLIOGRÁFICAS}

ALMEIDA, C.O.de; SOUZA, J. S.; CORDEIRO, Z.J.M. Aspectos Econômicos. In: MATSUURA, F.C. A.U.; FOLEGATTI, M.I.S. (Ed.) Banana. Pós-colheita. Brasília: Embrapa Informação Tecnológica, 2001.71p. (Frutas do Brasil, 16).

AMARO, A.A.; TSUNECHIRO, A.; VANSETTI, M.C.R. Abastecimento de centros urbanos: estudo do mercado varejista de piracicaba. Agricultura em São Paulo, São Paulo, v.36, n.1, p.99-125, 1989.

BALANÇO e disponibilidade interna de gêneros alimentícios de origem vegetal: 1986 a 1990. Rio de Janeiro: Fundação Getulio Vargas, 1991. $67 \mathrm{p}$.

BARROS, M.S. Mercado varejista de gêneros alimentícios da Grande São Paulo: uma abordagem estrutural. São Paulo: Secretaria de Agricultura, 1978. 52 p. (Relatório de pesquisa, 03/78).

BARROS, G.S.A.C. Economia da comercialização agrícola. Piracicaba: FEALQ, 1987.306p.

BRANDT, S.A. Comercialização agrícola. Piracicaba: Livroceres, 1980. 195p. 
CARVALHO, F.C. Perdas na comercialização de milho no Brasil e seus impactos sócio-econômicos. In: CONGRESSO NACIONAL DE MILHO E SORGO, 19., 1992, Porto Alegre. Conferências... p. 247-258.

FAO. Faostat database query. Disponível em: 〈http://www.fao.org/> Acesso em: 17 jun. 2002.

FRUTIFATOS: informação para a agricultura irrigada. Brasília: Ministério da Integração, 1999. v.1, 24 p.

IEA(Instituto de Economia Agrícola). Preços médios no mercado varejista. Disponível em: <http://www.iea.sp.gov.br/fbcoiea.htm> Acesso em: 17 jun. 2002.

JANK, M.S.; NASSAR, A.M. Competitividade e globalização. In: ZYLBERSZTAJN, D.; NEVES, M.F. (Coord) Economia e gestão dos negócios agroalimentares. São Paulo: Ed. Pioneira, 2000.

MASCARENHAS, G.C.C. Banana: Comercialização e mercados. Informe Agropecuário, Belo Horizonte, v. 20, n. 196, p. 97-108, jan/fev. 1999.

NATIONALACADEMY OF SCIENCES. Pérdidas de post-cosecha de alimentos en países en desarrollo. Trad. De Gonzalo Roa. Viçosa: Centro Nacional de Treinamento em Armazenagem, 1982.213p. (Série
CENTREINAR, 4).

SOUZA, A.T.; PEIXOTO, A. da N.; WAACHHOLZ, D. Banana. Florianópolis: Instituto de Planejamento e Economia Agrícola de Santa Catarina, 1995. 103 p. (Estudo de economia e mercado de produtos agrícolas, 2).

SPERS, E.E. A Segurança alimentar ao longo da cadeia. Conjuntura Alimentos, v.5, n. 1, p. 18-26, fev. 1993.

TSUNECHIRO, A.; UENO, L.H.; PONTARELLI, C.T.G. Avaliação econômica das perdas de hortaliças e frutas no mercado varejista da cidade de São Paulo, 1991/92. Agricultura em São Paulo, São Paulo, v. 41, n.2, p.1-15, fev. 1994.

UENO, L.H. Perdas na comercialização de produtos hortifrutícolas na Cidade de São Paulo. Informações Agronômicas, Piracicaba, v.63, p.5-7, março, 1976.

WEISS, J.; RAMPONI, R.M. Uma avaliação do sistema de comercialização de hortigranjeiros. Revista Economia Rural, v.19, n. 1, p. 69-86, jan/ mar. 1981 